\title{
Psychopharmacological Treatment Status in Outpatients with Bipolar Disorder: A Clinical Survey in Germany
}

\author{
Arnim Quante $^{1}$, Sara Zeugmann ${ }^{1}$, Francesca Regen ${ }^{1}$, Annette Engelhardt ${ }^{2}$ and Ion-George Anghelescu ${ }^{1}$ \\ ${ }^{1}$ Department of Psychiatry and Psychotherapy, Charité-University Medicine Berlin, Campus Benjamin Franklin, Berlin, Germany \\ ${ }^{2}$ Department Medical Affairs, Sanofi-Aventis Germany, Berlin, Germany
}

Objective The objective of this epidemiological study was to evaluate the current treatment status as well as the acceptance of medication and satisfaction with life in outpatients with bipolar disorder in Germany.

Methods Data for this cross-sectional epidemiologic survey was collected between February 15th, 2006 and May 31st, 2006. Three hundreds six bipolar euthymic outpatients under routine treatment conditions were included in the study. Forty one practicing psychiatrists used a clinical interview to evaluate the current treatment status, acceptance of current medication, and current life satisfaction.

Results The majority of patients suffered from "pure" bipolar-II-disorder (50.6\%), followed by $23.0 \%$ with "pure" bipolar-I-disorder. Apart from these patients, $12.9 \%$ of all participants had a history of mixed episodes and $5.6 \%$ a history of rapid cycling. Mean duration of bipolar disorder was 10.6 years. The majority of patients (54.3\%) received psychopharmacological monotherapy. Combination therapy was administered in $45.9 \%$ of the patients, $39.3 \%$ receiving two agents, and $6.6 \%$ three agents. Antidepressants (64.1\%) were the most common combination medications. Monotherapy was used preferably in bipolar-I- (62.7\%) and bipolar-II-disorders (56.2\%), combination therapy predominantly in patients with a history of mixed episodes (57.7\%) and rapid cycling (55.0\%). Half of the patients (49.2\%) were able to hold an occupation. $84.2 \%$ of all patients were satisfied with their medication. Overall, patients evaluated their life satisfaction between "good" and "satisfactory" (2.69 according to German school grades where 1 is the highest and 6 the lowest mark). Patients receiving lithium, valproate or antidepressants as monotherapy rated above the mean, patients with combination therapy, carbamazepine monotherapy or medications summarized as "others" rated below the mean.

Conclusion Most of the German outpatients received a pharmacotherapy that is recommended in the guidelines of bipolar disorder. The use of (atypical) antipsychotics was low. Conversely, the incidence of treatment with tricyclic antidepressants (not guideline compatible), was observed to be relatively high. Irrespective of their medication, in Germany patients with bipolar disorder show a high acceptance of their pharmacotherapy, and rate their life satisfaction as high. Nonetheless, half of the evaluated patients were not able to pursue a profession. Besides the disease age, gender and family life e.g., child care may also play a confounding role regarding the unemployment statistics.

Psychiatry Investig 2010;7:155-162

Key Words Bipolar disorder, Mania, Pharmacotherapy, Quality of life.

\section{INTRODUCTION}

Bipolar disorder is a serious disease with a lifetime prevalence of $0.8-1.5 \%$ for bipolar I disorder and up to $5 \%$ for the whole bipolar spectrum. ${ }^{1}$ Risk of death due to suicide is estimated to be approximately 20 times higher than that of the gen-

Received: February 18, 2010 Revised: March 30, 2010

Accepted: May 7, 2010 Available online: July 9, 2010

$\triangle$ Correspondence: Arnim Quante, MD

Department of Psychiatry and Psychotherapy, Charité-University Medicine Berlin, Campus Benjamin Franklin, Eschenallee 3, 14050 Berlin, Germany Tel: +49-30-8445-2272, Fax: +49-30-8445-8365

E-mail: arnim.quante@charite.de

(a) This is an Open Access article distributed under the terms of the Creative Commons Attribution Non-Commercial License (http://creativecommons.org/licenses/bync/3.0) which permits unrestricted non-commercial use, distribution, and reproduction in any medium, provided the original work is properly cited. eral population ${ }^{2}$ and, despite therapeutic efforts, the risk of a chronic course is relatively high. About $75 \%$ of the patients have a recurrent episode within five years. ${ }^{3}$ Bipolar patients have been estimated to spend approximately half of their lifetime being ill. ${ }^{4}$ The burden of disease is high, mainly in consequence of depressive episodes and symptoms. Depressive episodes last longer than the manic ones, they are harder to treat and cause patients to suffer more. ${ }^{1}$ The depression/mania ratio during the course of the disease is up to about $3: 1$. $^{4}$ Thus, bipolar patients suffer nearly half of their life (being ill) from bipolar symptoms, about three quarters of the time in consequence of depressive episodes and symptoms. ${ }^{5}$

Bipolar disorder has also serious socio-economic effects: according to the World Health Organization report (2000), bi- 
polar disorder is the tenth leading cause of disability. ${ }^{6}$

Concerning pharmacological treatment, there are several guidelines for bipolar disorder that recommend a monotherapy with mood stabilizers or atypical antipsychotics as the first line treatment. In cases of rapid cycling, mixed episodes, or severe manic episodes a combination therapy is recommended. The use of tricyclic antidepressants (TCA) or a monotherapy with antidepressants should be avoided because of the high "switching risk"?,

Incomplete control of bipolar disorder morbidity with monotherapeutic strategies has encouraged applications of various combinations of mood-stabilizing and other psychotropic agents in an effort to provide better symptomatic control. ${ }^{9}$ A combination therapy, especially in patients with manic episodes is nowadays routinely carried out in clinical practice: $90 \%$ of hospitalized manic inpatients are treated with a combination of a mood stabilizers and antipsychotic agents. Over the years, the significance of combination therapies has grown: between 1980 and 1984 about 10\% and between 1990 and 1994 about $45 \%$ of bipolar patients were treated with a combination of at least two medications. ${ }^{10} \mathrm{~A}$ combination therapy has also become more frequent in depressive episodes: Adding antidepressants to a mood stabilizer has increasingly become clinical practice in the treatment of moderate to severe depressive episodes, despite the inconsistent data for the use of antidepressants in these cases.$^{11,12}$ Moreover, combination therapy is often accompanied by more side effects which can be expected to affect the adherence to the recommended treatment negatively. ${ }^{13}$ The rate of partial or total nonadherence to mood stabilizers is approximately $51 \%$ for monotherapies with the common mood stabilizers (lithium, carbamazepine and valproate) ${ }^{14}$ and $48 \%$ for antipsychotics. ${ }^{15}$ There is only a very limited number of studies examining the effectiveness, as well as the safety and tolerability of combination therapies. ${ }^{16,17}$

Improvements in the quality of care in bipolar patients in the United States (US) were reported in a retrospective study comprising the years 1991-1999. The number of monotherapies with mood stabilizers had increased whereas monotherapies with antidepressants had decreased (which conforms with the guidelines). ${ }^{18}$

There are several factors complicating the treatment of bipolar disorder such as the adherence to treatment and a lack of life satisfaction or the life satisfaction issues. In general, risk factors for medication nonadherence include younger age, minoritiy ethnicity, limited family support, and a range of comorbidities, in particular substance abuse and personality disorders. ${ }^{15}$ Nonadherence predicts a less favourable course of treatment in terms of longer durations of hospitalization, higher likelihood of treatment switch or augmentation, higher inpatient charges, and higher rates of compulsory treat- ment. ${ }^{19,20}$ Unfortunatelly, long-term adherence to prescribed treatment is difficult to sustain in bipolar patients, especially during periods of euthymia or manic episodes.

In an epidemiologic study it was shown, that adherence is accompanied by higher life satisfaction: in comparison to nonadherent participants, adherent patients had fewer health problems and more resources for coping with stress. In addition to that, they also possessed a stronger belief that their own behaviors controlled their health status. ${ }^{21}$

With respect to the quality of life (QOL), outpatients with bipolar disorder have reported a significantly lower QOL compared to the general population. The number of symptoms correlated consistently negatively with QOL. ${ }^{22}$ Adverse effects of medication are also negatively associated with QOL on the physical and environment domains. ${ }^{23}$ To our knowledge, there are no comparison studies investigating differences in life satisfaction subject to different medications. However, it is known that the use of atypical antipsychotics is not associated with QOL, but subjects with bipolar disorder receiving olanzapine perceived better psychological QOL than those receiving risperidone and better psychological and social relationship QOL than those receiving no atypical antipsychotic. Despite reports about a lack of association between atypical antipsychotics and QOL variables, there is also evidence that bipolar patients receiving olanzapine perceive their QOL as higher compared to patients treated with risperidone. Furthermore they perceived themselves as having qualitatively better psychological and social relationships compared to patients who received no atypical antipsychotic medication. ${ }^{23}$ At present, there is a lack of data concerning patients' current medication status and the acceptance of prescribed pharmacotherapy in naturalistically treated bipolar outpatients in Germany.

The objective of this naturalistic and epidemiologic study was to assess the current medication status (such as monotherapy versus combination therapy) in bipolar patients, in particular with regard to the type of bipolar disorder (bipolar I or II) and type of episode (with or without a history of mixed episodes and rapid cycling). Moreover, acceptance of current pharmacotherapy and life satisfaction was assessed in relation to the current medication status.

\section{METHODS}

Patients with bipolar disorder were diagnosed according to the International Classification of Diseases, 10th Revision (ICD-10) criteria and clinical interviews by the attending psychiatrists.

The cross-sectional epidemiologic survey was conducted between February, 1st 2006 and May, 31st 2006 in Germany. The study was carried out by 41 voluntary participating psy- 
chiatrists in private practice, who were located in all parts of Germany, allowing an-approximately-representative estimation of the German patient population. The psychiatrists were informed about the survey and methods by letter and had the possibility to decide whether they want to participate or not. Three hundreds six outpatients with euthymic bipolar disorder were included, since they routinely came to the participating doctor during February, 1st 2006 and May, 31st 2006.

A case report form, prepared by cooperating psychiatrists, with the following parameters was developed and used:

-demographic data of patients, including birthday and sex

-history of medical treatment

-classification of bipolar disorder ("pure" bipolar-I or -II-disorder: defined as patients without mixed episodes or rapid cycling in their histories, versus patients with bipolar-I and -IIdisorder with a history of mixed episodes or rapid cycling)

-years of illness, illness symptoms and severity

-treatment status: current medication with dosage and duration of treatment

-acceptance of medication: we used a scale with the following 4 items: $1=$ =very good, $2=$ good, $3=$ bad or $4=$ no acceptance -hospitalizations in the last 24 months

-occupational status including the working time

-life satisfaction: a scale with 6 numeric items according to the German school grade systematics, in which lower numbers depict higher satisfaction (1=very good, $2=$ good, $3=$ satisfactory, $4=$ =fair, $5=$ poor, $6=$ unsatisfying) was used.

\section{Statistical analyses}

Statistical analyses employed commercial software (SPSS ${ }^{\circledast}$ 15.0 for windows).

Statistical analysis was preceded by a detailed plan. Data input was single data entry, but tests of plausibility were carried out and data was corrected if applicable. Since it was a crosssectional epidemiologic survey, statistical analyses was planned and performed in a descriptive character, therefore no sample size justification was done. Descriptive methods were used to analyze the data. The usual parameters were calculated for continuous data (number $\mathrm{n}$, mean, standard deviation, minimum, maximum). Qualitative data was described by means of absolute and relative frequencies. "Valid" percentages refer only to valid data, missing data were disregarded. If not otherwise stated, results were always presented for the entire study cohort. Types of medication were analyzed separately for the respective subgroups. Analyses of hospitalization and occupational status were performed for each medication subgroup separately. Additionally, subgroups concerning the individual mono- and combination therapies were created for the analyses of compliance and life satisfaction.

\section{RESULTS}

\section{Demographic data}

Altogether 356 outpatients from Germany participated in this survey. One hundred two (53.9\%) were female and 161 (45.2\%) male. The mean age was 47.5 years (18-85 years). Most of the patients were between 40 and 59 years (53.6\%). The mean duration of illness was 10.6 years (median 8 years) Figure 1.

\section{Type of bipolar disorder}

The current clinical status of all patients was euthymic. Interestingly, the majority of patients suffered from "pure" bipolar-II-disorder ( $\mathrm{n}=177 ; 50.6 \%)$, followed by 80 patients $(23.0 \%)$ with "pure" bipolar-I-disorder. Apart from these patients, 45 (12.9\%) of all participants had a history of mixed episodes and $20(5.6 \%)$ a history of rapid cycling. In $7.9 \%(n=28)$ of cases data were missing or disorder was classified as "others".

\section{Current treatment status}

Antidepressants were the type of medication most commonly used (24.3\%), followed by lithium (21.7\%), valproate (20.2\%) and carbamazepine (12.0\%). The most frequently applied antidepressants were serotonin-reuptake-inhibitors (SSRI) with $51.3 \%$, followed by TCA with $25.2 \%$.

The majority of patients ( $n=190 ; 54.3 \%)$ were treated with one medication (monotherapy). Concerning monotherapy, the

Figure 1. Age.

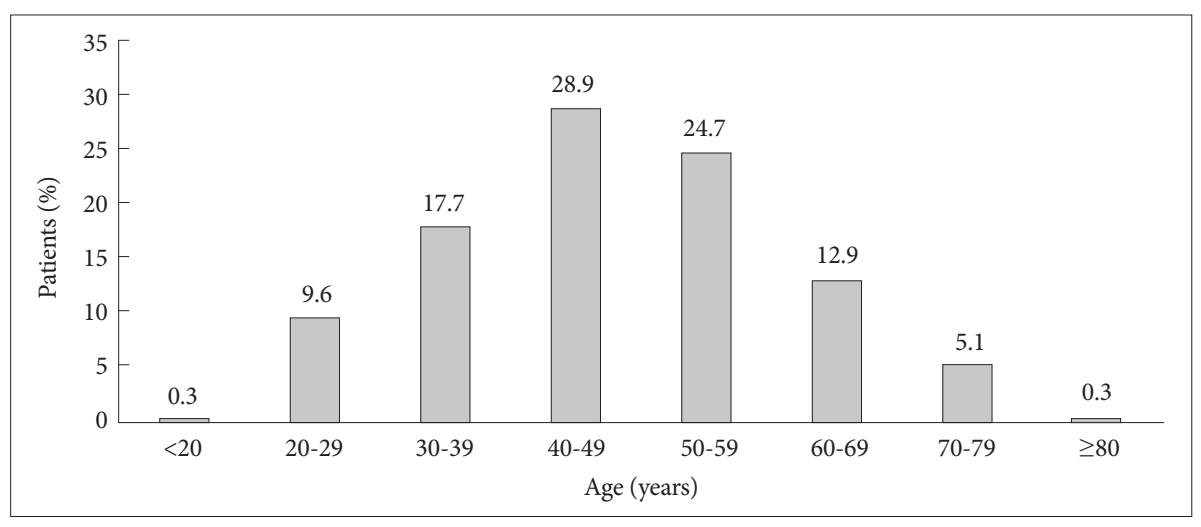


most frequently administered medication was valproate (27.9\%), followed by lithium (27.5\%), carbamazepine, antidepressants (both 14.2\%) and others (including antipsychotics and lamotrigine) (16.4\%). A combination therapy was used in altogether 160 patients (45.9\%). Whereof 137 patients (39.3\%) received a combination of 2 agents and 23 patients (6.6\%) of 3 agents (Figure 2). Most combination therapies included antidepressants (64.1\%), followed by lithium (43.4\%), valproate (34.5\%) and carbamazepine (23.4\%).

The treatment regime differed depending on the type of bipolar disorder: patients with the diagnosis of "pure" bipolar disorder received mainly monotherapy (bipolar-I 62.7\%, bipolar-II 56.2\%), whereas patients with a history of mixed episodes or rapid cycling frequently received combination therapy (mixed episodes $57.7 \%$, rapid cycling $55.0 \%$ ). In these patients, valproate was most commonly used both as monotherapy and in combination with other drugs (mixed episodes $37.7 \%$, rapid cycling $65.0 \%$ ).

Antidepressants were mostly used in patients with bipolarII-disorder (48.1\%). They were frequently applied in combination with other drugs. Only in "pure" bipolar patients they were also used as a monotherapy (bipolar-I-disorder 6.3\%, bipolar-II-disorder 11.9\%)(Table 1).

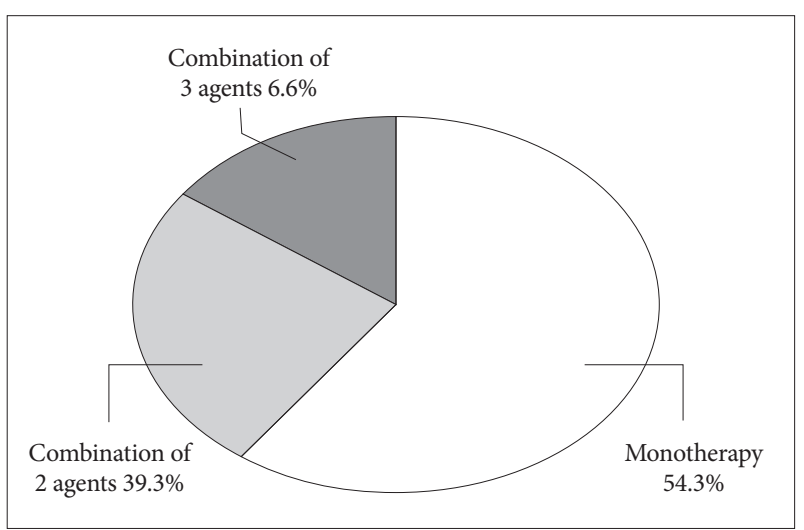

Figure 2. Current number of medications.

\section{Duration of treatment}

Concerning the duration of treatment, lithium was applied on an average of 7.0 years, carbamazepine for a period of 3.6 years, valproate 2.7 years and antidepressants 2.6 years. Among the antidepressants, TCAs were applied on average for 4.5 years and SSRI for a period of about 2.5 years. Except for lithium, the duration of treatment was longer when a combination therapy with an antidepressant was applied (Table 2, Figure 3).

\section{Hospitalisation and occupational status}

On average, patients were hospitalized 1.2 times within the last 24 months. There was no noteworthy difference between the different treatment groups with respect to hospitalization. Patients treated with valproate or lithium were hospitalized about 1.2 times, patients treated with carbamazepine 1.4 times, and patients treated with other drugs on average 1.3 times. Those treated with antidepressants had the lowest hospitalization rate of once during the last two years.

About every other patients $(n=172 ; 49.2 \%)$ was able to remain on a job. The mean working time was 31.7 hours per week. Again, there were no significant differences between the various treatment groups with respect to this variable. With an occupation rate of $56.2 \%$ and an average working time of 33.1 hours/week, patients treated with antidepressants were slightly outperforming the other treatment groups regarding the status of occupation.

Table 2. Mean durations of treatment (standard deviation)

\begin{tabular}{lc}
\hline Medication & $\begin{array}{c}\text { Duration of treatment } \\
\text { in years (standard deviation) }\end{array}$ \\
\hline Valproate & $2.7(2.5)$ \\
Lithium & $7.0(6.5)$ \\
Carbamazepine & $3.6(3.0)$ \\
Antidepressants & $2.6(3.0)$ \\
TCA & $4.5(4.1)$ \\
SSRI & $2.3(2.4)$ \\
\hline
\end{tabular}

Table 1. Quantities (percentages) of types of medication used in the respective subgroups

\begin{tabular}{lcccc}
\hline & "Pure" bipolar-I & "Pure" bipolar-II & Mixed episode & Rapid cycling \\
\hline Combination without antidepressant & 20.0 & 7.3 & 28.9 & 15.0 \\
Combination with antidepressant & 17.5 & 36.2 & 28.9 & 40.0 \\
Antidepressant MT & 6.3 & 11.9 & 6.8 & 0 \\
Carabamazepine MT & 8.8 & 13.0 & 15.6 & 0 \\
Lithium MT & 21.3 & 14.1 & 13.3 & 10.0 \\
Valproate MT & 17.5 & 31.3 & 33.3 & 25.0 \\
Combination without valproate & 26.3 & 12.4 & 24.4 & 15.0 \\
Combination with valproate & 11.3 & 10.7 & 4.4 & 40.0 \\
Others (incl. antipsychotics) & 8.8 & & & 10.0 \\
\hline
\end{tabular}

MT: monotherapy 
Of the patients treated with valproate, $48.1 \%$ were able to work for an average of 30.9 hours, whereas only $45.7 \%$ of the patients treated with lithium and $46.9 \%$ of the patients treated with carbamazepine were employed (mean working time 30.8 hours/week for lithium and 32.5 hours for carbamazepine treatment). Only $39.7 \%$ of the patients treated with other drugs (especially antipsychotics) were able to hold a job (mean working time 31.9 hours/week).

\section{Acceptance of medication}

To evaluate the acceptance of medication, a scale of four items was used (1=very good, $2=$ good, $3=$ bad, $4=$ no acceptance). Altogether, the acceptance was "good" (1.89). Two hundreds ninty four patients (84.2\%) were satisfied with their medication.

Two hundreds four patients (58.4\%) rated the acceptance of their medication as being "good", 90 patients $(25.8 \%)$ even rated it as being "very good". Only 49 patients (14.1\%) were not content with their current medication, $13.5 \%$ had a "bad" acceptance of their medication, and $0.6 \%$ did not accept the medication at all. In $1.7 \%$ of cases data were missing. However, there were no differences between the medication groups in this matter (Figure 4).

\section{Life satisfaction}

To evaluate life satisfaction, a scale with 6 numeric items according to the German school grade system was used (1=very good, 2=good, 3=satisfactory, 4=fair, 5=poor, 6="unsatisfying). Missing data were within $0.6 \%$ of cases.

Overall, patients evaluated their life satisfaction between "good" and "satisfactory" (mean 2.69). Half of the patients ( $\mathrm{n}=$ $171 ; 49.1 \%$ ) rated their satisfaction as being "good" or "very good", whereas 113 patients (32.3\%) rated "satisfactory" and 43 patients (12.4\%) "fair". Only 19 patients (5.6\%) were not content, which was mirrored in their ratings of "poor" or "unsatisfying".

Differentiated life satisfaction between the medication statuses, there were no significant differences between all medication groups. However, patients on a monotherapy with lithium, valproate or antidepressants showed a slight trend to be more content with their life than patients treated with a carbamazepine monotherapy, a combination therapy, or with other medications like antipsychotics (Figure 5).

\section{DISCUSSION}

To our knowledge, this is the first clinical survey examining the current treatment status in German outpatients with

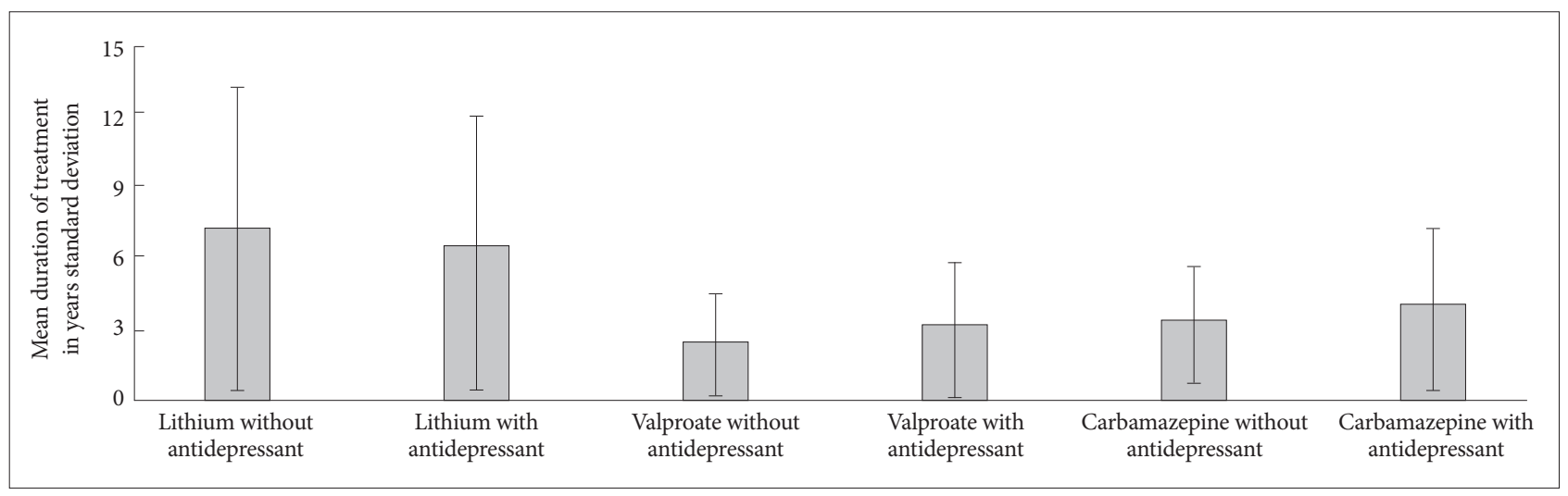

Figure 3. Mean duration of treatment in years for the different antidepressant combinations (standard deviation).

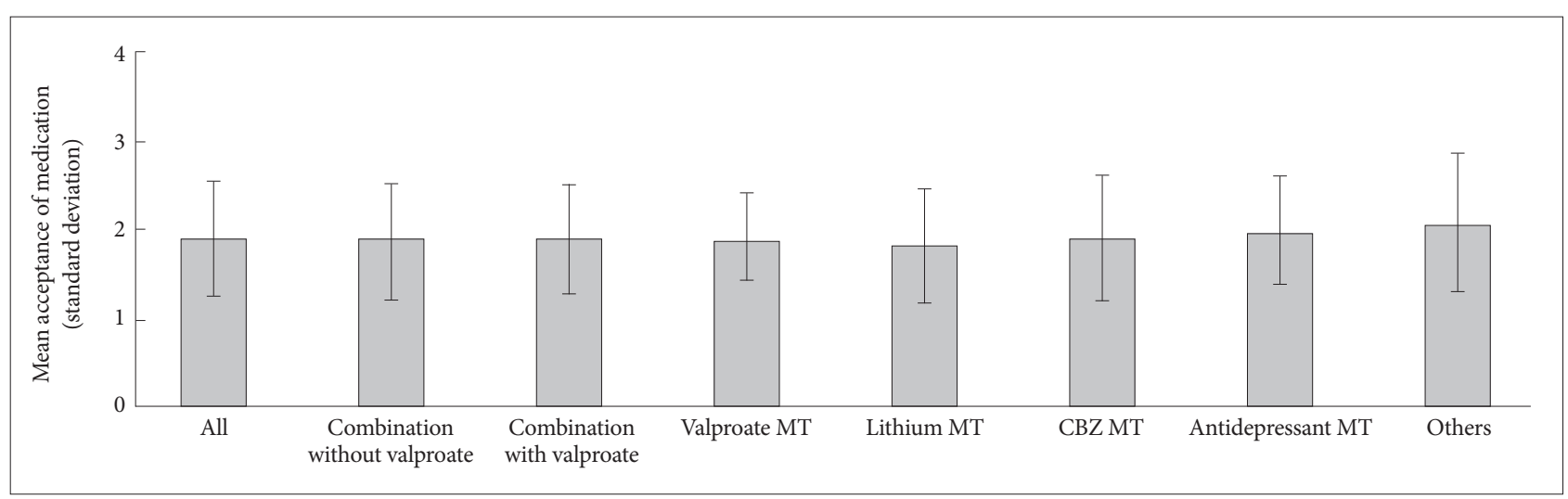

Figure 4. Mean acceptance of medication (standard deviation). 1: very good, 2: good, 3: bad, 4: no acceptance. MT: monotherapy, CBZ: carbamazepine. 


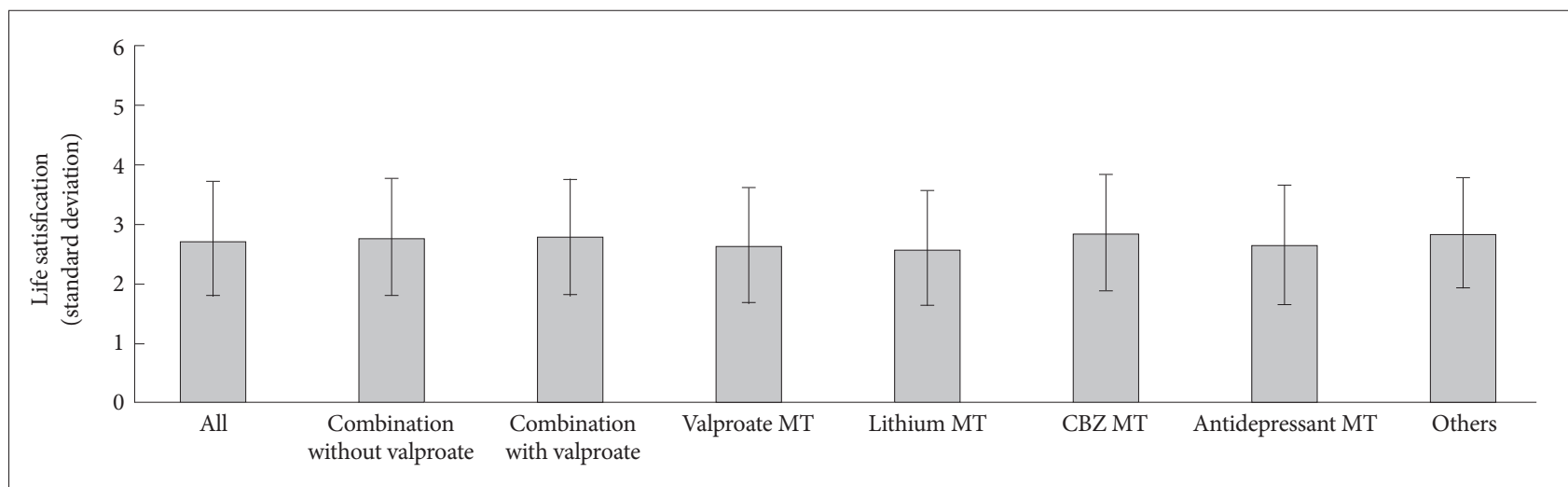

Figure 5. Life satisfaction according to German school grade (standard deviation). 1: very good, 2: good, 3: satisfactory, 4: fair, 5: poor, 6: unsatisfying. MT: monotherapy, CBZ: carbamazepine.

bipolar disorder. Surprisingly, the majority of patients in this study population suffered from bipolar-II-disorder, which is quite uncommon. However, in the last years more and more clinical investigations put its focus on bipolar disorder, which may lead to a higher alertness in diagnosing even hypomanic episodes. The majority of outpatients assessed received a pharmacotherapy as recommended in the guidelines for bipolar disorder. However, since guideline recommendations are only hesitantly implemented into clinical practice, the reasons for these facts should be examined to further improve clinical care for this chronically ill population. Contrary to the growing trend, the application of atypical antipsychotics was rather low. Presumably, high costs for atypical antipsychotics and restricted budgets of the medical practitioners could be a cause for this observation.

In a study by Baldessarini et al. ${ }^{24}$ the current treatment status of US bipolar patients was examined: in this cohort, $61.3 \%$ received antipsychotics, and $76.2 \%$ a combination with at least 2 medications. Only half of our patients were treated with a combination of psychopharmacological substances, which is, comparable to other data in the literature, quite low and may reflect the higher proportion of patients with bipolar-II-disorder.

On the other hand, in comparison to treatment regimes in the past, it also reflects and confirms the growing trend for combination therapies in bipolar disorder, especially in patients with a history of rapid cycling and mixed episodes. There seem to be no differences in life satisfaction according to the treatment statuses. However, in our study population some patients receiving a monotherapy with lithium, valproate, or antidepressant seem to be trendwise more content with their life than patients receiving a combination therapy. This may indicate better tolerance of monotherapy.

On the other hand, patients receiving a combination therapy may have more severe and/or more frequent episodes which per se may decrease life satisfaction.
According to the guidelines of bipolar disorder, a monotherapy with antidepressants is not recommended. ${ }^{7.8}$ In our cohort, only a few patients received a monotherapy with antidepressants. Surprisingly, TCA, which have a high switch rate, are used more frequently than serotonin reuptake inhibitors. This suggests that quality of care needs further improvements. Antidepressants were the most frequently used substance class for combination therapy. Importantly, it has to be pointed out that, there is some data suggesting that antidepressants in bipolar patients do not have positive effects on bipolar depression. ${ }^{11}$ Thus, the prescription of antidepressants in bipolar patients seems to continue being popular despite the data being inconsistent and their administration being controversial.

Patients with a history of rapid cycling were frequently treated with valproate either in combination or as a monotherapy. This may reflect better effectiveness of valproate in these patients and supports the conclusions of other studies, that valproate, even in combination, may be more effective in patients with a history of rapid cycling. ${ }^{25,26}$ Lithium seems to be an apt long term medication; the duration of treatment with lithium was on an average of 7 years, whereas the duration of treatment with other medications was much shorter.

The occupational status of $49.2 \%$ in our study population is comparable with other data in the literature. Besides the disease age, gender and family life e.g., child care may also play a confounding role regarding the unemployment statistics. There were no significant differences between the patients when grouped according to their medications. Still, antidepressants outperformed the other substances slightly as we observed a trend for higher employment rates and more working hours in patients treated with them. Despite of the controversial discussion concerning antidepressants in bipolar disorder, they might have putative positive effects in long-term treatment. In a study of Altshuler et al. ${ }^{27}$ a depressive relapse of patients with bipolar disorder was significantly associated 
with discontinuation of antidepressants after remission, which also may indicate the importance of antidepressants in this disorder.

To our knowledge, this is the first study to collect data on the effects of medication on occupational status in bipolar patients. Further studies focusing on this are strongly needed because improvements in the ability to work will putatively lead to better life satisfaction and lower costs for the health care system. Contrary to the low adherence rates in bipolar patients in other studies, the acceptance of the medication in our population was very good. Importantly though, it has to be differentiated between the concepts of acceptance and adherence, the latter of which we did not actually assess explicitly.

In other studies, adherence is measured by other instruments, e.g., by intensity (with the medication possession ration) and treatment duration. ${ }^{20}$ Adherence measurements should be implemented for further surveys and also should be correlated with the current medication status.

Concerning life satisfaction, most of the patients were contented or satisfied. As a limiting factor, we did not use standardized measurements for QOL like the World Health Organisation's Quality of Life Assessment Instrument-Bref (WHOQOF-Bref). ${ }^{28}$

We also did not implement a questionnaire for the current symptoms, like the Symptoms Checklist- $90,{ }^{29}$ to correlate it with the QOL and the treatment status. It is well documented that bipolar disorder greatly affects QOL. Moreover, even patients who are symptom free or in a stable euthymic state can have lowered QOL. ${ }^{22}$ In further studies, such measurements should be implemented, especially to make the results internationally comparable.

\section{Acknowledgments}

The study was developed and managed by Sanofi-Aventis, Germany. The statistical analysis was performed by "Pharma Direkt GmbH".

\section{REFERENCES}

1. Angst J, Sellaro R. Historical perspectives and natural history of bipolar disorder. Biol Psychiatry 2000;48:445-457.

2. Sharma R, Markar HR. Mortality in affective disorder. J Affect Disord 1994;31:91-96.

3. Tohen M, Hennen J, Zarate CM Jr, Baldessarini RJ, Strakowski SM, Stoll AL, et al. Two-year syndromal and functional recovery in 219 cases of first-episode major affective disorder with psychotic features. Am J Psychiatry 2000;157:220-228.

4. Kupka RW, Altshuler LL, Nolen WA, Suppes T, Luckenbaugh DA, Leverich GS, et al. Three times more days depressed than manic or hypomanic in both bipolar I and bipolar II disorder. Bipolar Disord 2007; 9:531-535.

5. Judd LL, Akiskal HS, Schettler PJ, Endicott J, Maser J, Solomon DA, et al. The long-term natural history of the weekly symptomatic status of bipolar I disorder. Arch Gen Psychiatry 2002;59:530-537.

6. The World Health Organisation. The World Health Report 2000-Health Systems: Improving Performance. [Homepage: http://www.who. int/whr/2000/en/]. 2000.

7. Yatham LN, Kennedy SH, O’Donovan C, Parikh SV, MacQueen G, McIntyre RS, et al. Canadian Network for Mood and Anxiety Treatments (CANMAT) guidelines for the management of patients with bipolar disorder: update 2007. Bipolar Disord 2006;8:721-739.

8. Practice guideline for the treatment of patients with bipolar disorder (revision). Am J Psychiatry 2002;159:1-50.

9. Baldessarini RJ, Perry R, Pike J. Factors associated with treatment nonadherence among US bipolar disorder patients. Hum Psychopharmacol 2008;23:95-105.

10. Miller DS, Yatham LN, Lam RW. Comparative efficacy of typical and atypical antipsychotics as add-on therapy to mood stabilizers in the treatment of acute mania. J Clin Psychiatry 2001;62:975-980.

11. Sachs GS, Nierenberg AA, Calabrese JR, Marangell LB, Wisniewski SR, Gyulai L, et al. Effectiveness of adjunctive antidepressant treatment for bipolar depression. N Engl J Med 2007;356:1711-1722.

12. Leverich GS, Altshuler LL, Frye MA, Suppes T, McElroy SL, Keck PE Jr, et al. Risk of switch in mood polarity to hypomania or mania in patients with bipolar depression during acute and continuation trials of venlafaxine, sertraline, and bupropion as adjuncts to mood stabilizers. Am J Psychiatry 2006;163:232-239.

13. Baldessarini RJ. Enhancing treatment with psychotropic medicines. Bull Menninger Clin 1994;58:224-241.

14. Keck PE Jr, McElroy SL, Strakowski SM, Bourne ML, West SA. Compliance with maintenance treatment in bipolar disorder. Psychopharmacol Bull 1997;33:87-91.

15. Sajatovic M, Valenstein M, Blow FC, Ganoczy D, Ignacio RV. Treatment adherence with antipsychotic medications in bipolar disorder. Bipolar Disord 2006;8:232-241.

16. Lin D, Mok H, Yatham LN. Polytherapy in bipolar disorder. CNS Drugs 2006;20:29-42.

17. Baethge C, Baldessarini RJ, Mathiske-Schmidt K, Hennen J, Berghofer A, Muller-Oerlinghausen B, et al. Long-term combination therapy versus monotherapy with lithium and carbamazepine in 46 bipolar I patients. J Clin Psychiatry 2005;66:174-182.

18. Busch AB, Ling D, Frank RG, Greenfield SF. Changes in the quality of care for bipolar I disorder during the 1990s. Psychiatr Serv 2007;58:27-33.

19. Eaddy M, Grogg A, Locklear J. Assessment of compliance with antipsychotic treatment and resource utilization in a Medicaid population. Clin Ther 2005;27:263-272.

20. Gianfrancesco FD, Sajatovic M, Rajagopalan K, Wang RH. Antipsychotic treatment adherence and associated mental health care use among individuals with bipolar disorder. Clin Ther 2008;30:1358-1374.

21. Darling CA, Olmstead SB, Lund VE, Fairclough JF. Bipolar disorder: medication adherence and life contentment. Arch Psychiatr Nurs 2008; 22:113-126.

22. Goossens PJ, Hartong EG, Knoppert-van der Klein EA, van AT. Selfreported psychopathological symptoms and quality of life in outpatients with bipolar disorder. Perspect Psychiatr Care 2008;44:275-284.

23. Yen CF, Cheng CP, Huang CF, Yen JY, Ko CH, Chen CS. Quality of life and its association with insight, adverse effects of medication and use of atypical antipsychotics in patients with bipolar disorder and schizophrenia in remission. Bipolar Disord 2008;10:617-624.

24. Baldessarini R, Henk H, Sklar A, Chang J, Leahy L. Psychotropic medications for patients with bipolar disorder in the United States: polytherapy and adherence. Psychiatr Serv 2008;59:1175-1183.

25. Freeman TW, Clothier JL, Pazzaglia P, Lesem MD, Swann AC. A double-blind comparison of valproate and lithium in the treatment of acute mania. Am J Psychiatry 1992;149:108-111.

26. Calabrese JR, Rapport DJ, Kimmel SE, Reece B, Woyshville MJ. Rapid cycling bipolar disorder and its treatment with valproate. Can J Psychiatry 1993;38:S57-S61.

27. Altshuler L, Suppes T, Black D, Nolen WA, Keck PE, Frye MA, et al. Impact of antidepressant discontinuation after acute bipolar depres- 
sion remission on rates of depressive relapse at 1-year follow-up. American Journal of Psychiatry 2003;160:1252-1262.

28. The World Health Organization Quality of Life Assessment (WHOQOL): development and general psychometric properties. Soc Sci Med
1998;46:1569-1585.

29. Ardinell WA, Ettema JH. Symptom Checklist 90; SCL-90. Amsterdam: Harcourt Assessment B V;2005. 